\section{(2) OPEN ACCESS}

${ }^{1}$ Gorgas Memorial Institute for Health Studies, Panama, Panama

2PAHO/WHO Tobacco Control Focal Point, Health Ministry of Panama, Panama, Panama

\section{Correspondence to}

Dr Hedley Quintana, Research and Health Technology Assessment Department, Instituto Conmemorativo Gorgas de Estudios de la Salud, Panama 0816-02593, Panama; hquintana@gorgas.gob.pa

Received 2 March 2020 Revised 31 July 2020 Accepted 4 August 2020
Check for updates

(c) Author(s) (or their employer(s)) 2020. Re-use permitted under CC BY-NC. No commercial re-use. See rights and permissions. Published by BMJ.

To cite: Quintana H, Roa R. Tob Control Epub ahead of print: [please include Day Month Year]. doi:10.1136/ tobaccocontrol-2020-055736

\title{
Tobacco use and access among 13 to 15 year olds in Kuna Yala, an indigenous region of Panama
}

\author{
Hedley Quintana 지, ${ }^{1}$ Reina Roa ${ }^{2}$
}

\begin{abstract}
Background Panama has the lowest overall prevalence of tobacco use in the Americas, however rates are almost three times higher in the indigenous territory of Kuna Yala compared with the national average. Most people who smoke started during adolescence, making this a key period for tobacco control efforts.
\end{abstract}

Objective We aimed to examine tobacco access and use among adolescents (13 to 15 years old) in Kuna Yala compared with nationwide Panama using data from the 2017 Global Youth Tobacco Survey, a standardised international tool for assessing key tobacco control indicators among adolescents.

Results The prevalence of current tobacco use among 13 to 15 year olds in Kuna Yala was $14.0 \%(95 \% \mathrm{Cl}$ : $11.6 \%$ to $16.9 \%$ - $-a l m o s t$ twice the national average of $7.8 \%(95 \% \mathrm{Cl}: 6.3 \%$ to $9.4 \%)$. Half of all adolescents in Kuna Yala estimated the cost of a 20-cigarette pack as less than US\$0.75, compared with $16.2 \%$ of adolescents across of Panama ( $p$ value $<0.01$ ).

Conclusions Kuna Yala is one of the few indigenous territories in Spanish-speaking countries where key tobacco control indicators have recently been assessed. Higher tobacco use and lower reported cigarette prices in that region may be linked with the presence of barter economy which may give adolescents more ready access to cigarettes than in other parts of Panama. There is a need for more indigenous-specific data to help build the evidence base to improve tobacco control and reduce commercial tobacco use among indigenous peoples.

\section{INTRODUCTION}

The WHO estimates that tobacco consumption causes nearly eightmillion deaths per year, including one million in the Americas. ${ }^{1}$ Most people begin using tobacco before the age of $18,{ }^{2}$ making adolescence a key period for tobacco control efforts. Rates of commercial tobacco use are often higher in indigenous populations, ${ }^{3}$ although data on these communities is often limited or masked by reporting at a whole-of-population level.

Panama has the lowest recorded tobacco use in the Americas, with a prevalence of $9.4 \%$ in men and $2.8 \%$ in women according to the Global Adult Tobacco Survey. ${ }^{4}$ While cigarettes (manufactured and hand-rolled) are the most common form of smoked tobacco, cigars are also commonly used in Panama. ${ }^{4}$ However, the same survey shows that Kuna Yala, Panama's second-most populated indigenous territory, has much higher smoking rates of $26.5 \%$ in men and $7.9 \%$ in women. ${ }^{4}$

Panama was one of the first countries to ratify the WHO Framework Convention on Tobacco Control $(\text { FCTC })^{5}$ and has one of the most developed national tobacco control programmes in the Americas. ${ }^{6}$ Consistent with FCTC Article $16,{ }^{5}$ Panama has a national law ${ }^{6}$ that prohibits the sale of tobacco to anyone under the age of 18 , including in indigenous territories such as Kuna Yala. Panama's population has a relatively young age structure, with over $27 \%$ of its total population (around four million people) aged less than 15, compared with an average of less than 24\% for the Americas. ${ }^{7}$ Panama's indigenous communities constitute $12.3 \%$ of the total population. $^{8}$

Kuna Yala is a largely indigenous territory in northeast Panama with a population of around 44231 in 2017, most of whom belong to the Kuna indigenous community. The population of 13 to 15 year olds in Kuna Yala in the same year was $3304 .{ }^{9}$ We aimed to assess current use of tobacco and access to commercial cigarettes among 13 to 15 year olds living in Kuna Yala, and to compare this with use and access among 13 to 15 year olds in Panama as a whole.

\section{METHODS}

We assessed tobacco usage and access among adolescents in Kuna Yala and elsewhere in Panama based on the Global Youth Tobacco Survey (GYTS). The GYTS provides a global standard for monitoring youth tobacco to track key tobacco control indicators. It is a school-based survey of secondary school students aged 13 to 15 years, using a standardised protocol and questionnaire. ${ }^{10}$

In 2017, the GYTS was undertaken in Panama using a two-stage cluster sample design to produce a nationally representative sample. It was conducted in Spanish with 2096 students from 25 schools throughout Panama. While all schools with students aged 13 to 15 years were included in the sampling frame-including those in primarily indigenous territories-in practice no schools from Kuna Yala were selected for inclusion in the main GYTS survey.

Alongside the national GYTS, we used the same protocol and questionnaire to undertake a census of students aged 13 to 15 years $(n=1083$ students) in Comarca Kuna Yala from 27 schools in the territory. While most students in Kuna Yala schools are from the Kuna community, one school in Puerto Obaldía (in the eastern part of the territory) includes a significant proportion of non-indigenous students. In order to maintain appropriate ethical standards and confidentiality, we included all 13- to 15 -year-old students in the survey and did not distinguish on the basis of school or indigenous status. The Kuna Yala version of the GYTS was administered in Spanish, but questions were clarified in the Kuna language if necessary. 


\section{Indicators}

Key tobacco indicators were constructed using core questions from the Panamanian version of the GYTS questionnaire. ${ }^{11}$ Selected tobacco control indicators from the tobacco 'use' and 'access and availability' components of the 2015 GYTS Analysis and Reporting Package ${ }^{12}$ were used to generate the following indicators for 13 to 15 year olds in Kuna Yala and in Panama:

- Current use of any tobacco products (with 'current use' defined as use during the last 30 days);

- Current cigarette smoker (ie, respondents who had smoked cigarettes on at least one of the past 30 days);

- Estimated cost of a pack of 20 (choosing from a range of options) among those who estimated the price;

- Current cigarette smokers who were not prevented from buying cigarettes in the past 30 days because of their age;

- Means of acquiring most recently-smoked cigarette(s) among current cigarette smokers; and

- Purchase of cigarettes as individual sticks (singles) in the last 30 days among current cigarette smokers.

\section{Statistical analysis}

The prevalence of specific indicators was estimated and compared between respondents from Kuna Yala and the rest of Panama, after excluding missing data. Taking account of complex sampling weights and uncertainty, 95\% CI and $\chi^{2}$ tests were calculated using the 'survey' package V.3.36 for R V.4.02.

\section{Data availability}

The 2017 Panama GYTS belongs to the Global Tobacco Surveillance System (GTSS), and the data can be requested through the GTSSData website. ${ }^{13}$ The 2017 Kuna Yala GYTS are available on request from the authors.

\section{Ethical statement}

The GYTS is administered anonymously according to guideline 16 of the WHO Guidelines on Ethical Issues in Public Health Surveillance. $^{14}$

\section{RESULTS}

Current tobacco use was higher among adolescents in Kuna Yala compared with the country as a whole, but current cigarette use was similar in both places (table 1). This apparent discrepant finding regarding tobacco use and cigarette smoking is due to higher consumption of other than cigarette smoked tobacco products among Kuna Yala students compared with the country as a whole $(7.1 \%$ Kuna Yala students vs $2.4 \%$ in Panama as a whole, $\mathrm{p}$ value $<0.001)$. Tobacco use, as well as cigarette smoking, was notably higher among male adolescents and older students in Kuna Yala, while these distinctions were much less apparent in Panama as a whole.

Half of the students from Kuna Yala estimated that the cost of a 20-cigarette pack was US\$0.75 or less, while fewer than $20 \%$ of students in schools nationwide made similar estimate. Fewer than 5\% of students from Kuna Yala estimated that the cost of a 20-cigarette pack was US\$4.01 or more, while $13.7 \%$ of students nationwide made a similar estimate. These results were consistent by gender and age.

Among adolescents who were current cigarette smokers (ie, who smoked cigarettes on at least one of the past 30 days), those living in Kuna Yala were more likely to report that their age had not prevented them from buying cigarettes in the last 30 days. Limited numbers meant prevalence estimates were somewhat imprecise and differences were not statistically significant,
Table 1 Current use of tobacco products and price assessment of a 20-pack of cigarettes. The Global Youth Tobacco Survey 2017

\begin{tabular}{|c|c|c|c|}
\hline & $\begin{array}{l}\text { Kuna Yala } \\
\%(95 \% \mathrm{Cl})^{*}\end{array}$ & $\begin{array}{l}\text { Panama } \\
\%(95 \% \mathrm{Cl})^{*}\end{array}$ & P valuet \\
\hline \multicolumn{4}{|c|}{ Current tobacco use (ie, use of any tobacco product in the past 30 days) } \\
\hline All adolescents aged 13 to 15 & 14.0 (11.6 to 16.9$)$ & $7.8(6.3$ to 9.5$)$ & $<0.01$ \\
\hline Male adolescents & 18.6 (14.9 to 23.1$)$ & 7.9 (6.2 to 9.8$)$ & $<0.01$ \\
\hline Female adolescents & $9.6(7.0$ to 13.1$)$ & $7.4(5.4$ to 10.0$)$ & 0.24 \\
\hline All adolescents aged 13 years & $10.9(7.2$ to 16.0$)$ & 7.4 (5.2 to 10.3$)$ & 0.13 \\
\hline All adolescents aged 14 years & 14.8 (10.7 to 20.1$)$ & 7.4 (5.7 to 9.6$)$ & $<0.01$ \\
\hline All adolescents aged 15 years & 17.4 (13.1 to 22.8$)$ & $9.0(6.0$ to 13.4$)$ & $<0.01$ \\
\hline \multicolumn{4}{|c|}{ Current cigarette smoker (ie, smoked cigarettes on at least 1 day in the past 30 days) } \\
\hline All adolescents aged 13 to 15 & $5.0(3.1$ to 5$)$ & 4.0 (3.6 to 6.0$)$ & 0.14 \\
\hline Male adolescents & $8.0(5.4$ to 10$)$ & $4.2(3.1$ to 6.0$)$ & $<0.01$ \\
\hline Female adolescents & $2.0(1.1$ to 4.0$)$ & $3.4(2.5$ to 5.0$)$ & 0.13 \\
\hline All adolescents aged 13 years & $2.2(1.1$ to 4.0$)$ & $3.4(2.2$ to 5.0$)$ & 0.25 \\
\hline All adolescents aged 14 years & $4.3(2.3$ to 7.0$)$ & $4.2(3.0$ to 6.0$)$ & 0.91 \\
\hline All adolescents aged 15 years & $9.9(6.4$ to 13.0$)$ & $4.3(2.7$ to 7.0$)$ & $<0.01$ \\
\hline \multicolumn{4}{|c|}{ Estimating the cost of a pack of 20 cigarettes: less than US $\$ 0.75$} \\
\hline All adolescents aged 13 to 15 & 49.7 (42.9 to 56.6$)$ & 16.2 (12.6 to 20.7) & $<0.01$ \\
\hline Male adolescents & 47.7 (39.7 to 56.2 ) & $17.0(13.2$ to 21.6$)$ & $<0.01$ \\
\hline Female adolescents & $52.4(42.2$ to 62.4$)$ & 15.3 (11.1 to 20.8$)$ & $<0.01$ \\
\hline All adolescents aged 13 years & 57.1 (47.6 to 66.1) & 18.6 (13.6 to 24.9$)$ & $<0.01$ \\
\hline All adolescents aged 14 years & 43.9 (32.7 to 55.6$)$ & 15.1 (10.7 to 20.8$)$ & $<0.01$ \\
\hline All adolescents aged 15 years & 44.8 (33.7 to 56.5$)$ & $14.8(10.1$ to 21.1$)$ & $<0.01$ \\
\hline \multicolumn{4}{|c|}{ Estimating the cost of a pack of 20 cigarettes: US $\$ 4.00$ or more } \\
\hline All adolescents aged 13 to 15 & 2.7 (1.5 to 4.9$)$ & $13.8(10.1$ to 18.6$)$ & $<0.01$ \\
\hline Male adolescents & $2.0(0.8$ to 5.1$)$ & 13.7 (9.8 to 18.8$)$ & $<0.01$ \\
\hline Female adolescents & 3.7 (1.6 to 8.6$)$ & 13.6 (9.2 to 19.7$)$ & $<0.01$ \\
\hline All adolescents aged 13 years & $2.2(0.7$ to 6.8$)$ & 11.2 (8.3 to 15.2$)$ & $<0.01$ \\
\hline All adolescents aged 14 years & $5.0(2.1$ to 11.1$)$ & 15.0 (10.7 to 20.5$)$ & $<0.01$ \\
\hline All adolescents aged 15 years & $1.1(0.1$ to 7.7$)$ & 15.7 (9.3 to 25.6$)$ & $<0.01$ \\
\hline
\end{tabular}

however, with an estimated $64.8 \%$ (95\% CI: $42.1 \%$ to $82.3 \%$ ) of 13 - to 15 -year-old smokers in Kuna Yala and 58.4\% (95\% CI: $49.5 \%$ to $69.0 \%$ ) in Panama reporting they had not been prevented from buying cigarettes because of their age. This indicator could not be examined by gender and/or age due to small sample size.

The percentage of current cigarette smokers who bought their last cigarette in a store or shop and/or as an individual stick were similar for adolescents in Kuna Yala (48.9\%; 95\% CI: $29.3 \%$ to $68.7 \%)$ and nationwide $(58.7 \%$; $95 \% \mathrm{CI}$ : $39.8 \%$ to $75.4 \%$ ). While the small sample size limited our ability to demonstrate significant differences (table 2), our findings suggest that adolescents in Kuna Yala may be more likely to acquire cigarettes from a street vendor while those elsewhere in Panama are more likely to access them from a vending machine or some other source.

\section{DISCUSSION}

Panama has the lowest prevalence of tobacco use in the Americas, ${ }^{15} 16$ reflecting its comprehensive suite of tobacco control measures. ${ }^{6}$ At the same time, our data suggest that tobacco use may be substantially higher in indigenous communities such as those living in Kuna Yala. Current tobacco use among 13 to 15 year olds in Kuna Yala was estimated at 14.1\%—almost twice the nationwide prevalence in this age group (7.8\%). Use of other than cigarettes smoked tobacco appears common among adolescents in Kuna Yala-among whom around a half of tobacco users 
Table 2 Means of acquiring cigarettes among current cigarette smokers. 2017 Global Youth Tobacco Survey

\begin{tabular}{|c|c|c|c|}
\hline & $\begin{array}{l}\text { Comarca } \\
\text { Kuna Yala } \\
\%(95 \% \mathrm{Cl})^{*}\end{array}$ & $\begin{array}{l}\text { Panama } \\
\%(95 \% \mathrm{Cl})^{*}\end{array}$ & $P$ valuet \\
\hline Bought them in a store or shop & $22.7(10.0$ to 43.4$)$ & 22.7 (13.2 to 36.2$)$ & 0.99 \\
\hline Bought them from street vendor & 17.8 (7.0 to 38.4$)$ & 10.9 (4.5 to 24.0$)$ & 0.36 \\
\hline $\begin{array}{l}\text { Bought them from kiosk or } \\
\text { supermarket }\end{array}$ & 0 & 0 & - \\
\hline $\begin{array}{l}\text { Bought them from a vending } \\
\text { machine }\end{array}$ & 3.6 (1.3 to 23.3$)$ & $6.0(0.5$ to 19.9$)$ & 0.63 \\
\hline Got them from someone else & 50.6 (34.7 to 66.1$)$ & $45.4(34.1$ to 57.2$)$ & 0.59 \\
\hline Got them from other means & $2.8(0.3$ to 19.1$)$ & $17.4(7.7$ to 34.8$)$ & 0.04 \\
\hline
\end{tabular}

There was a current cigarette smoker who did not answer this question.

${ }^{*} \mathrm{Cl}$, taking into account complex sampling.

$+\chi^{2}$ test per row, taking into account complex sampling.

represented products other than cigarettes. These findings are consistent with differences in adult smoking prevalence reported in the most recent Global Adult Tobacco Survey, ${ }^{4}$ which found adult smoking prevalence in Kuna Yala was almost three times higher than in other parts of Panama. Among adults in Kuna Yala also had a higher tendency to use other than cigarettes smoked tobacco products, particularly cigars.

While cigarettes account for only one element of tobacco use among adolescents in Kuna Yala (and the most commonly used tobacco product elsewhere in Panama), they represent the most standardised form and thus provide a useful basis for assessing and comparing access. We were not able to demonstrate significant differences in how adolescents obtain cigarettes in Kuna Yala compared with elsewhere in Panama, although our findings suggest young people in Kuna Yala may face less age-related difficulty in purchasing cigarettes and are more likely to make use of street vendors. Around half of all adolescent smokers-in both Kuna Yala and elsewhere in Panama-obtained their last cigarette from another person, suggesting social sources are particularly significant for this age group in both indigenous and non-indigenous populations. Over half of all adolescent smokers are able to purchase cigarettes despite their age, suggesting imperfect implementation of Panama's age-of-sale legislation.

Male adolescents in Kuna Yala were more susceptible to becoming smokers than those living elsewhere in Panama, while female adolescents had similar risk regardless of where they lived. These patterns suggests important intersections between indigenous status and gender, which may have implications in considering how best to prevent tobacco uptake among young people and indigenous men in this region.

The average retail price of a legal 20-cigarette pack was >US\$5.00 in Panama in 2017. Half of 13 to 15 year olds in Kuna Yala substantially underestimated this price (by more than $80 \%$ ), compared with only $16 \%$ of adolescents elsewhere in Panama. Low estimates of cheap cigarettes among Panamanian adolescents are consistent with a previous report which did not find evidence that smokers in Panama were accessing very low-priced cigarette packs. ${ }^{16}$ One possible explanation for much higher estimates of cheap cigarettes in Kuna Yala is the existence of a significant informal (barter) economy in this region. Comarca Kuna Yala has a tradition of informal exchange of various products-including tobacco ${ }^{17}$-reflecting the historical practice of bartering with passing Colombian cargo ships, and potentially also the deliberate smuggling of illicit tobacco by the tobacco industry. ${ }^{18}$ The availability of cheap tobacco via this informal market may make it difficult for adolescents in this region to accurately estimate the cost of commercial cigarettes.

The disproportionate harms of commercial tobacco for indigenous populations are an ongoing challenge for global tobacco control. ${ }^{3}$ The FCTC acknowledges this in its preamble, which states that parties are "Deeply concerned about the high levels of smoking and other forms of tobacco consumption by indigenous peoples". 5 However, there are limited official data regarding key tobacco control indicators among indigenous populations in Latin America. Although some reports exist, ${ }^{19}$ these are limited and data are often somewhat dated.

Data on tobacco use and access are seldom reported at the subnational level, which makes it difficult to determine the scale of tobacco use or the extent to which progress is being made in tobacco control among indigenous populations. In alignment with the FCTC's recognition of the particular needs of indigenous peoples, ${ }^{5}$ it is essential that we develop more consistent reporting of tobacco indicators in indigenous populations. Such data should be included as part of standard FCTC reporting in order to ensure that commitments to reducing tobacco use are being met for all population groups.

Strengthening FCTC reporting instruments to include indigenous-specific data and more detailed information on other tobacco forms (besides cigarettes) will help realise the guiding principles of the FCTC, building the evidence base and momentum to improve tobacco control and reduce commercial tobacco use among indigenous peoples.

\section{CONCLUSIONS}

Adolescents in the indigenous territory of Kuna Yala have much higher tobacco use than those in other parts of Panama, which helps explain why adults in this region have around three times the national smoking rate. Relatively low cigarette prices and a significant informal economy may facilitate tobacco access among young people in Kuna Yala, contributing to the region's higher smoking rates. There is a clear need to address the harms of tobacco use in Kuna Yala and in other indigenous communities in Latin America and worldwide. Strengthening FCTC reporting instruments to include indigenous-specific data and developing partnerships between health authorities and indigenous communities are essential steps towards improving indigenous health and reducing tobacco-related harms.

\section{What this paper adds}

- There is limited evidence on tobacco use among indigenous communities in Latin America.

- We found much higher tobacco use among 13 to 15 year olds living in a predominantly indigenous region of Panama (Kuna Yala), where adolescent smoking prevalence was almost twice as high as in the rest of Panama

- Relatively low cigarette prices and a significant informal economy may facilitate access and contribute to higher tobacco use among adolescents living in Kuna Yala.

- Strengthening WHO Framework Convention on Tobacco Control reporting instruments to include indigenousspecific data will help build the evidence base to improve tobacco control and reduce commercial tobacco use among indigenous peoples.

Acknowledgements We acknowledge Dr Fulvia Bajura and the Ministry of Health of Panama personnel working with all the health regions that helped us to collect data. We would like to thanks Dr Rogelio Montoya, a local health authority officer 
who conducted the Global Youth Tobacco Survey in Comarca Kuna Yala together with his team. HKQ receives support from the Sistema Nacional de Investigación (SENACYT).

Contributors Conceptualisation, $\mathrm{HQ}$ and RR; formal analysis, HQ; investigation, HQ; data curation, HQ; writing — original draft preparation, HQ and RR; writingreview and editing, HQ and RR. All authors have read and agreed to the published version of the manuscript.

Funding The authors have not declared a specific grant for this research from any funding agency in the public, commercial or not-for-profit sectors.

Competing interests None declared.

Patient consent for publication Not required.

Provenance and peer review Not commissioned; externally peer reviewed.

Open access This is an open access article distributed in accordance with the Creative Commons Attribution Non Commercial (CC BY-NC 4.0) license, which permits others to distribute, remix, adapt, build upon this work non-commercially, and license their derivative works on different terms, provided the original work is properly cited, appropriate credit is given, any changes made indicated, and the use is non-commercial. See: http://creativecommons. org/licenses/by-nc/4.0/.

ORCID iD

Hedley Quintana http://orcid.org/0000-0002-5929-8791

\section{REFERENCES}

1 PAHO, Regional Office for the Americas of the World Health Organization. Tobacco prevention and control [website]. Available: https://www.paho.org/en/topics/tobaccoprevention-and-control [Accessed 22 Jun 2020].

2 World Health Organization. WHO report on the global tobacco epidemic, 2011: warning about the dangers of tobacco. Geneva:World Health Organization, 2011. http://www.who.int/tobacco/global_report/2011/en/index.html

3 Minichiello A, Lefkowitz ARF, Firestone M, et al. Effective strategies to reduce commercial tobacco use in Indigenous communities globally: a systematic review. BMC Public Health 2016;16:21.

4 Gómez Quintero B, González B, Niño C, et al. Encuesta mundial de tabaco en adultos, una visión desde la perspectiva regional, 2013. Panamá, Panama: Ministerio de Salud, 2016.

5 World Health Organisation framework convention on tobacco control (FCTC). Available: https://apps.who.int/iris/bitstream/handle/10665/42811/9241591013.pdf; jsessionid=AEA279C2A1C303B12BEC97CA8DCFE325? sequence $=1$ [Accessed 13 Jan 2020].
6 Asamblea Nacional de Panama. Ley 13: Que adopta medidas para el control del tabaco y sus efectos nocivos en la salud. In the Spanish language. Available: https:/ www.gacetaoficial.gob.pa/pdfTemp/25966/8638.pdf [Accessed 10 Jan 2020].

7 PAHO. PLISA health information platform for the Americas. Washington, D.C: Pan American Health Organization, 2020. https://www.paho.org/data/index.php/en/

8 Instituto Nacional de Estadística y Censo/Contraloría General de la Republica de Panama. Cuadro 1. Estimación y proyección de la población de la República, Según sexo y edad: al 1 de JULIO de 2010-20. Available: http://www.inec.gob.pa/archivos/ P4991CUADR01.xls [Accessed 15 Jan 2020].

9 Instituto Nacional de Estadística y Censo/Contraloría General de la Republica de Panama. Cuadro 11. Estimación y proyección de la Población de la Comarca kuna yala, según sexo y edad: al 1 de Julio de 2010-20. Available: http://www.inec.gob.pa/ archivos/P4991CUADR011.xls [Accessed 15 Jan 2020].

10 PAHO. Global youth tobacco survey (GYTS). Available: https://www.paho.org/hq/ index.php?option=com_content\&view=article\&id=13432: gyts\&ltemid $=42359 \&$ lang=en [Accessed 18 Jul 2020].

11 Global Youth Tobacco Survey Collaborative Group. Global youth tobacco survey (GYTS): core questionnaire with optional questions, version 1.2. Atlanta, GA: Centers for Disease Control and Prevention, 2014.

12 Global Youth Tobacco Survey Collaborative Group. GYTS analysis and reporting package. Available: https://www.paho.org/hq/dmdocuments/2017/4-GYTS-Analysis andReportingPackage-v1.1-Jan2015.pdf [Accessed 6 Jan 2020].

13 CDC (GTSSData). GTSS tobacco surveillance system data. Available: https://www.cdc. gov/tobacco/global/gtss/gtssdata/index.html

14 World Healh Organization. WHO guidelines on ethical issues in public health surveillance. Geneva: World Health Organization, 2017. ISBN: 978-92-4-151265-7. https://apps.who.int/iris/bitstream/handle/10665/255721/9789241512657-eng.pdf; jsessionid=F7191B380AD098ECE777FEB95D4FE46D? sequence $=1$

15 Quintana HK, Roa R. Panama a small country with a huge story of success in tobacco control health policies. Nicotine Tob Res 2019:ntz230.

$16 \mathrm{PAHO} / \mathrm{WHO}$. Report on tobacco control in the region of the Americas 2018. Available: http://iris.paho.org/xmlui/handle/123456789/49237 [Accessed 13 Jan 2020].

17 Ballesteros H, Hugo V. Encuesta de mercado de cigarrillos 2015. Distritos de Panamá, San Miguelito, Colón, David, Barú y Comarcas Ngäbe Buglé y Kuna Yala. in the Spanish language. Available: http://www.gorgas.gob.pa/aplicaciones/revistanoindexadas/pdf/13\% 20Est_MercadoCigarrillo2015.pdf [Accessed 13 Jan 2020].

18 WHO Framework Convention on Tobacco Control Secretariat. The tobacco industry and the illicit trade in tobacco products. Available: https://www.who.int/fctc/ publications/The_TI_and_the_Illicit_Trade_in_Tobacco_Products.pdf [Accessed 17 Jan 2020].

19 Alderete E, Kaplan CP, Gregorich SE, et al. Smoking behavior and ethnicity in Jujuy, Argentina: evidence from a low-income youth sample. Subst Use Misuse 2009;44:632-46. 